\section{DENIAL OF ILLNESS}

By E. A. Weinstein, M.D., and R. L. KahN, Ph.D. Pp. viii + 166. Oxford: Blackwell Scientific Publications. 1955. 34s.

Here for the first time is a detailed holistic account of anosognosia and the many related forms in which denial of illness can appear. Eight years of intensive research into behavioural changes in brain pathology have enabled the authors to develop a unitary theory embracing hitherto unrelated patterns of reaction to altered states of brain function. Anatomical, electro-physiological and psychological evidence is carefully used to show the importance of the centrencephalic involvement as a milieu for anosognosic symptoms, and many widely held hypotheses relating to the latter, including those of parietal focus and 'Body Image' defects, are shown to be untenable. Proceeding with strict scientific conformity, the authors use their own hypotheses for predictive purposes, and prove their point by experimental production.

Of particular interest is the relation which anosognosic symptomatology bears to the postleucotomy behaviour, and the authors show that the success or failure of such psychosurgery will depend upon which type of denial the patient adopts as his adaptation to changes in cerebral functioning. Taken in conjunction with the chapters on personality changes and psychometric results, this particular chapter offers a basis on which prognosis of leucotomy can be carefully assessed, and in addition, techniques for determining the presence of intracranial pathology not indicated clinically are given. The authors have already published this information elsewhere in greater detail, and it seems unfortunate that fuller treatment was not given to this important aspect in the book. The reviewer also felt the need for a summarising chapter, and hopes that future editions will make good this omission.

The Appendix contains pathological, neurological, EEG and CSF, and behavioural data on 104 patients showing anosognosia, the tables being dichotomised into implicit and explicit denial of illness, and including those patients whose case-histories appear in the text. This book will provide a source of much fruitful discussion in all branches of medicine, while to the clinical psychologist it will prove to be one of the most important books of the year.

\section{NEUROCHEMISTRY. THE CHEMICAL DYNAMICS OF BRAIN AND NERVE}

Edited by K. A. C. Elliott, M.Sc., Ph.D., IRvine H. PAGe, M.D., and J. H. Quastel, D.Sc., PH.D., F.R.C.S., F.R.S., with 32 contributors. Pp. xii +900 , illustrated. Oxford: Blackwell Scientific Publications. 1955. £7.

At the end of the last century scientists were commonly more catholic in their choice of interests than they are today. Thudichum, who in 1884 published his classical book'A Treatise on the
Chemical Constitution of the Brain,' in the following year produced 'The Spirit of Cookery' and 'A Treatise on Wines' in 1886 . Although the volume under review does not cover as wide a field of interest as that of the 'father of the chemistry of the brain' to whom it is dedicated, it is, nevertheless, a remarkable collection of articles on many aspects of neurochemistry. While it is invidious to select any particular chapter for especial praise, one cannot help being impressed by the range of selection of workers of international reputation who have so ably contributed to this volume. Hoagland, Kety, Nachmanson and Racker from the United States, Dickens, Penrose and Peters from Great Britain, Von Euler and Heyden from Sweden, Quastel, Bergen and MacIntosh from Canada, to mention only a few. Tre book terminates with a short but stimulating cha ter by Wiener on the 'Thermodynamics of the Me ssage.'

Without exception the standard of every chapter is high, together with the comprehensive references and author and subject indexes. This book should be considered as probably the most up-to-date summary of the present views on a wide variety of topics concerned with the study of neurochemistry. It should find a well deserved place in all medical libraries and is a useful and stimulating reference book for workers in the field.

\section{FLUID AND ELECTROLYTES IN PRACTICE}

By Henry Statland, M.D. Pp. xiii +206 , with 30 diagrams. London: Pitman Medical Publishing Co. Ltd. 1955. 35s.

This book meets the widespread demand for a concise account of the physiology and pathology of the body fluids in times which the practising clinician can readily understand. Unlike the majority of the books of this type written so far, it deals with the subject in a quantitative manner so that the physician or surgeon at the bedside can interpret the reports of his laboratory colleagues and translate them into a measure of a particular patient's disorder and therapeutic needs. Dr. Statland divides his book into two sections, the first dealing with the normal physiology of the body fluid compartments and the simple disorders which can occur in them, and the second dealing with the specific biochemical features in various common disease processes. His description of the rational methods of therapy in electrolyte disorders is admirable, although perhaps to many clinicians on this side of the Atlantic the volumes of intravenous solutions suggested in daily fluid schedules would seem rather large.

This monograph can be strongly recommended to medical students, for whom indeed it was written, and the subject matter dealt with is vital to their understanding of many clinical problems.

B.J.H. 